\title{
Insights from Stimulating Creative Behaviours in a Project-Based Organization Team
}

\author{
Tracy Stanley, Judy Matthews, and Paul Davidson
}

\author{
"We believe that ideas only become great") \\ when they are challenged and tested. \\ Ed Catmull \\ President of Pixar Animation Studios \\ In Creativity, Inc.
}

\begin{abstract}
Novel and useful ideas and creative behaviours originate in varied work environments, yet the characteristics of work environments that stimulate and foster such creative behaviours are not well defined. The aim of this study was to identify the influences that contribute to creative behaviours in the work environment of a global project-based professional service organization. This article is based on an investigation of the work environment of one project team undertaking interdisciplinary work in the construction of a processing plant in a remote location. This multi-disciplinary team encouraged creative behaviours through regular team meetings, ensuring the presentation of diverse views and commitments to regular interaction and collaboration in co-located environments. In addition, a technology manager dedicated to identifying potential opportunities for patenting and commercialization further extended the creative behaviours of the team by focusing on the best solution for each situation. The study contributes new knowledge to research regarding work environments that facilitate creative behaviours.
\end{abstract}

\section{Introduction}

Organizational creativity is the creation of a valuable and useful new product, service, idea, procedure, or process by individuals working together in a complex social system (Woodman et al., 1993). Broadly defined, innovation is the successful application of ideas (Matthews, 2002). Innovation depends on ideas generated through creativity and the knowledge and research that make it possible to put ideas to work (Naggar, 2015). Companies that can develop and implement creative ideas perform better in changing operating situations, with CEOs recognizing the value of empowering and mobilizing the collective brainpower of the workforce for innovation (IBM, 2010). Further research into creative processes and their antecedents across different types of organizations, jobs, and teams is confirmed as an obvious priority (Gilson \& Shalley, 2004).

The study described in this article was framed to gain insight into these antecedents in work environments. It features an investigation of the characteristics of work environments that generate creative behaviours within one project team in a medium-sized, global, consulting engineering, project-based organization.

This study contributes new knowledge to research regarding work environments that facilitate creative behaviours by highlighting the processes used when diverse, interdisciplinary employees meet in regular design review meetings, which stimulate individual and collective creative behaviours. These behaviours, further extended by a technology manager, support the creation and capture of innovative solutions that also deliver commercial value for the company.

We begin by considering extant research regarding links between creative behaviours and work environments, before outlining methodology and describing findings and concluding with practical implications.

\section{Work Environments and Creative Behaviours}

Work environments that encourage creative behaviours have previously been defined in R\&D teams (Amabile, Hadley, \& Kramer, 2002) and in the animation and film 


\section{Insights from Stimulating Creative Behaviours in a Project-Based Organization Team}

\section{Tracy Stanley, Judy Matthews, and Paul Davidson}

industry (Catmull, 2008), but less attention has been given to other work environments. The research question we are addressing is: What are the characteristics of work environments that encourage creative behaviours in a project-based organization? A review of literature across work environments and creative behaviours follows.

Creative behaviours appear to result from the complex interactions between the person and situation (Amabile, Conti, Coon, Lazenby, \& Herron, 1996; Woodman et al., 1993). They emerge in response to challenging work, openness to new ideas, and an experimental mindset (Woodman et al., 1993). Creative behaviours focus on the initial phases of the innovation process, that is the idea generation, exploration stage to the exclusion of the implementation stages (Kanter, 1988; Shalley \& Gilson, 2004). Examples of creative behaviours include searching out new technologies and suggesting new ways to achieve objectives (West, 2002). Results of creative behaviours could range from suggestions for incremental adaptations in procedures, to radical and major breakthroughs in the development of new products (Mumford \& Gustafson, 1988).

Major contributions to understanding work environments have come from Amabile and colleagues (1996) through their work on the KEYS model for measuring environmental components that work as either stimulants or obstacles to creative behaviours. An interactional perspective of the complex social systems influencing organizations was developed by Woodman, Sawyer, and Griffin (1993). Team climate factors influencing team behaviours were investigated by Anderson and West (1998) and Isaksen and Ekvall (2010), while Dul and Ceylan (2011) considered influences on a work environment to have personal, social-organizational and physical factors. Recent research emphasizes the importance of synthesizing divergent perspectives in the idea-generation process focusing on the nature of the team work environment (Hackman, 2011).

Previous research indicates several characteristics and mechanisms that influence creative behaviours in team-based work environments, including i) the behaviour of the manager (Hennessey \& Amabile, 2010), ii) design of work (Shalley, 2004), iii) provision of time for creativity (Dul \& Ceylan, 2011), iv) attitude to risk (Dulaimi et al., 2002; Hartmann, 2006), v) existence of positive versus negative tensions (Isaksen et al., 2001; Shalley \& Gilson, 2004), vi) effective management of different types of conflict (Jehn, 1995; Pelled, 1996), vii) ex- tent of collaboration within and across teams (Taylor \& Greve, 2006; Thompson \& Choi, 2005), vii) level of participation in decision making (Harvey \& Kou, 2013), ix) existence of an effective process for creativity management (Smith et al., 2008), and $\mathrm{x}$ ) positive social relationships (Amabile \& Gryskiewicz, 1989; Hennessey \& Amabile, 2010), among others. Many factors appear to be operating together in a cumulative and complex manner within the work environment. An understanding of the nature and characteristics of these factors invites further research, and a project-based organization provides a new context (Stanley et al., 2014).

The nature of work environments has previously been investigated through a variety of methods. These include semi-structured interviews using the critical incident technique to explore best and worst team environments (Amabile et al., 2002), examination of daily diaries (Amabile et al., 2004), ethnographic studies (Sutton \& Hargadon, 1996), and work environment questionnaires (Amabile et al., 1995). This study employed qualitative data collection processes within a single case study, as described in the following section.

\section{Methodology}

Investigation of the generation of creative behaviours was undertaken using qualitative research within a case study. A case study is the strategy of choice when the focus is on understanding the dynamics present within single settings, and when existing theory seems inadequate (Eisenhardt, 1989). Internet research was used to identify an organization with a commitment to innovation and a history of commercial success through innovation for this study.

The team discussed in this article, (renamed "Team Delta" to maintain confidentiality), was the management team within a new project, and employed some thirty staff. Management team members were highly experienced engineers. Half had more than 10 years' experience with the company and several members possessed advanced academic qualifications. Team Delta was working on the delivery of a large and highly specialized plant in the Middle East in a joint venture, using technology patented by the organization. The project required teams with diverse expertise and skills in areas of design, mechanical, structural, and electrical engineering, as well as piping, scheduling, and project management. The discipline expert managers from each of these specialist teams, known as "leads", were among the managers interviewed for this study. 


\section{Insights from Stimulating Creative Behaviours in a Project-Based Organization Team}

\section{Tracy Stanley, Judy Matthews, and Paul Davidson}

Eight of the ten members of the management team were interviewed face-to-face in semi-structured interviews for the study and were present when observations of meetings were undertaken. Eight team members interviewed represented seven nationalities; seven were male and one was female; and they represented diverse skillsets and ethnic origins. Observations were made in two of the weekly project status meetings. No observations were undertaken of the design review meetings. Data collection in this team occurred over a three-month period and data were thematically analyzed and coded for categorization using the qualitative data analysis program software NVivo.

\section{Findings}

Work was undertaken within a staged project management framework with key milestones. Within a projectbased organization, agreements with key stakeholders largely define the scope of work, the project deliverables, and project outcomes. The leads then established planning and procedures for implementation with their respective teams, working closely with other teams through the design review meetings for all interdisciplinary-related impacts. Frequent design review meetings provided a forum for discussing and agreeing on all design-related matters and weekly project status meetings reviewed achievements against the project plan. A dedicated technology manager provided technical process expertise and ensured a specific focus on identification of patent-creation opportunities. The team was based in two locations for the duration of the three-year project with regular visual electronic communication between sites during team meetings.

Findings regarding creative behaviours and the work environment related to the nature of the work itself, manager behaviours, team processes, and the physical work environment. Challenges arising in the project were related both to the nature of the work and to relationships between team members. From a task perspective, the nature of work undertaken was multifaceted, requiring significant interdisciplinary integration and collaboration. From a relationship perspective, managing a large team in a joint venture with a competitor added complexity in terms of confidentiality and the generation and protection of intellectual property. This team had a clear focus on identifying and formalizing innovations through patents to achieve commercial organizational benefits.

\section{Nature of work}

The characteristics found to most consistently contribute to creative behaviours throughout the build included the presence of a challenging problem or task. For example, challenges could arise because of the space limitations at the plant site or from the need for careful integration between the disciplines while ensuring compliance with scope and safety standards. Team members reported that many solutions to problems or current challenges emerged when they were jointly investigating problems in regular design review meetings or reporting on project completion activities in the project status meetings. However, the design review meeting was the principal forum for exploring and agreeing on all design-related aspects of the build:

"Well, the new ideas come from design reviews. I have a minimum of three design reviews at the moment. As we get busier, I'll be having five, six, seven, eight design reviews. This is around the model, talking about different aspects. You have multi-disciplinary teams and we talk about specifically drilling down to problems: How can we operate this? What's he doing? Why is he doing it? Can we do it any better? Is there another product which we can use which is better?" (Lead 1)

The team used both formal and informal processes for responding to challenges, collaborating, and getting the work done. Collaboration occurred in multiple settings, including informal discussions in the workplace and specifically in meetings such as the team's design review meeting. Some of the creative behaviours inherent in the idea generating and shaping process are illustrated in Figure 1.

New ideas were particularly welcomed in the design review meetings during the early stages of the project when there was a greater capacity to explore new approaches, test them out, and implement workable solutions. As the project progressed, the nature of work became more tightly defined, with less possibility for exploring new approaches. The frequency of design review meetings compared to the weekly status meetings may have been related to the early stage of the project and the importance of idea generation, testing, and refinement.

The staged project management framework, with flexibility for exploration and refinement of ideas at design review meetings and the constraints of key milestones, encouraged rich discussion and enforced debate and 


\section{Insights from Stimulating Creative Behaviours in a Project-Based Organization Team} Tracy Stanley, Judy Matthews, and Paul Davidson

\author{
- Respond to requests from clients \\ - Take photos of client problems \\ -Analyze a problem collaboratively \\ - Explore multiple perspectives in \\ detail \\ -Be open to new ideas
}

- Ask questions

- Provide contextual information

- Frame problems in new ways

- Have informal conversations

- Challenge viewpoints

- Explore alternatives

- Undertake experiments

- Develop prototypes

-Ask more questions

- Continually test solutions with whole team

- Assess commercial value and patent potential

Figure 1. Creative behaviours and idea development process

agreement between key stakeholders. The idea management process starts with ideas and suggestions in the "stimulate" phase. Ideas are floated, discussed, debated, and evaluated in the "shape and nurture" phase before a final decision is made at the point of "capture". At the beginning of the project, there is greater latitude for all build options. However, as decisions are made, future decisions become constrained by previous decisions. The idea management process becomes more focused as the project develops, with the milestone reviews putting pressure on all team members to come to agreement on all design-related aspects that need to be finished by these points. The development of ideas is clearly an iterative process that aligns with models for incorporating learning in project teams (Davidson \& Rowe, 2009). The idea-shaping process is mapped in Figure 2.

\section{Relationships, roles, and behaviours}

Team Delta demonstrated mixed levels of collegiality and cohesiveness. Furthermore, a shared sense of pro- fessionalism and of valuing working on this project appeared to help to move the project along. Decisions where specific disciplines had expertise and a stake in the outcomes could be a source of friction. Behaviours that contributed to confrontations were sometimes seen as negative by team members, although it was recognized that conflict can facilitate deeper evaluation of alternatives, experimentation and better decisionmaking processes. This finding confirmed reports in extant literature (Isaksen et al., 2001; Jehn, 1995; Pelled, 1996; Shalley \& Gilson, 2004). Indeed, to some extent, disagreement was able to drive higher levels of creativity as team members sought to prove or disprove their own or other team members' technical proposals, leading to productive experimentation and evaluation.

The idea-generation process was influenced by how employees felt about engaging in debate, as well as time constraints. Team members recognized that, for a change of approach to be accepted, getting the "buyin" of other senior staff and particularly of the techno- 


\section{Insights from Stimulating Creative Behaviours in a Project-Based Organization Team}

Tracy Stanley, Judy Matthews, and Paul Davidson
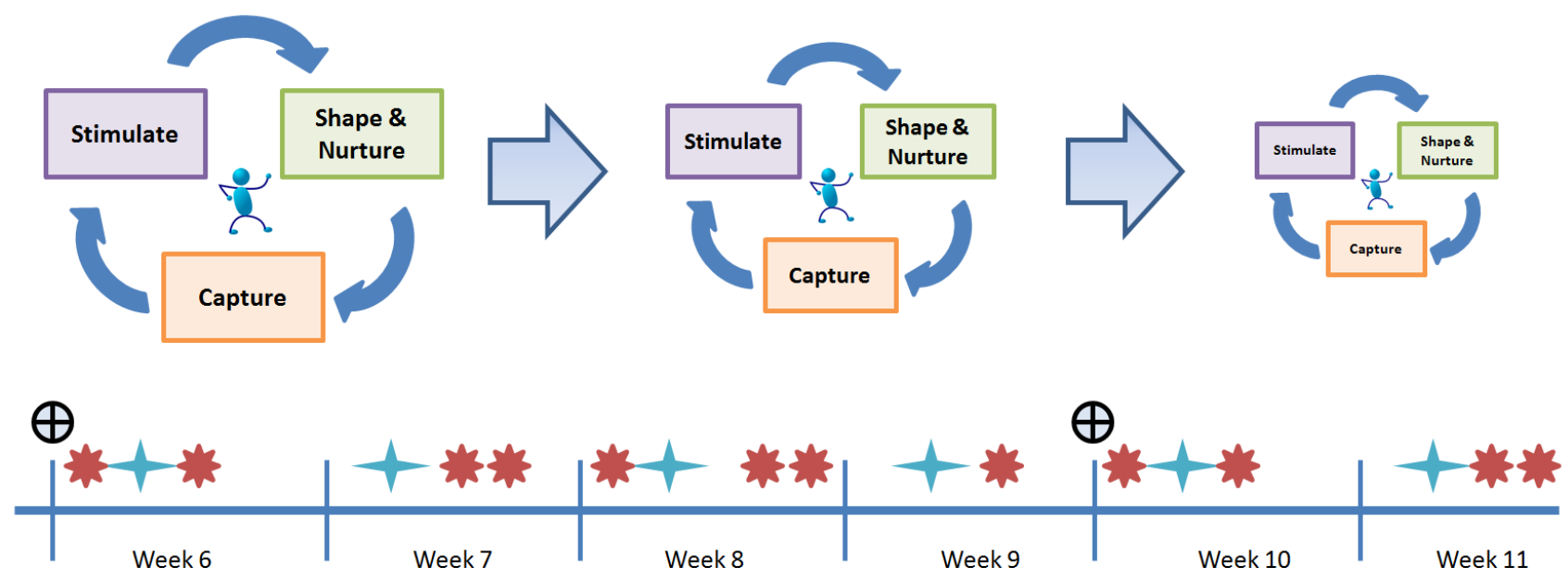

Design review meeting

Milestone review

Figure 2. Idea development and shaping process in project management

logy manager, whose role is key in the innovation identification and formalization process, was necessary. In addition to acting as an expert on process, this manager actively looked for opportunities to commercialize knowledge throughout the project and was described as being very forceful in the pursuit of new knowledge:

“...Sometimes [the technology manager] comes with the ideas that he wants... but he doesn't know exactly how to do it. So, we have to come up with the way to do it. And sometimes he's pushing us back. So we say: It can't be done. He says: No, think about it. Think about how it can be done. And then eventually: Oh, yes. Maybe we can do this. So he's pushing, pushing, pushing..." (Lead 2)

\section{Conclusions}

Creative behaviours apparent in Team Delta included the generation of ideas to approach different problems, challenging assumptions based on past experience, seeking new perspectives from team members, rigorous discussion, evaluating of alternatives, disagreement, collaboration, and experimentation. Many characteristics that influence creative behaviours found in this study confirm previous research. Examples include the richness of ideas that emerge from cross-functional teams and the use of multi-disciplinary team meetings to focus on exploration of ideas, discussion, debate, and agreement. Findings are particularly relev- ant for project-based organizations seeking to achieve project management objectives of quality work that is on time, on schedule, and within budget. In addition, this team was seeking innovative approaches and outcomes that could be patented. Findings also highlight the value of structured approaches to managing discussions and decision-making processes. Distinct processes used in the design review meetings, where many of the creative behaviours were noted, and milestone reviews had different but complementary objectives related to idea management and achievement tracking.

The role of a technology manager with a dedicated focus on the identification and commercialization of new knowledge was an initiative that appeared to demand new ways of working from the team members. Challenging team assumptions and including dissenting opinions can generate energy, which fosters richer discussions, better quality decisions, and an increased capacity to identify unique knowledge that adds value and can possibly be patented.

Practical implications from this research for project managers include the identification of local work processes such as interdisciplinary team meetings for debating and agreeing on all aspects of the build; use of a dedicated role to spot innovation potential opportunities; valuing and management of disagreement/contrary views as a stimulant to creative behaviours such as evaluation of ideas and experimentation; and norms of es- 


\title{
Insights from Stimulating Creative Behaviours in a Project-Based Organization Team
}

\author{
Tracy Stanley, Judy Matthews, and Paul Davidson
}

tablishing team cultures with clear expectations of teamwork. The systematic stimulation, testing, and refinement of ideas through design review meetings and weekly progress meetings, with collaboration, collegiality, and well-managed contestation all contributed to a work environment supportive of creative behaviours. This team illustrates the power of learning within knowledge-intensive firms (Starbuck, 1992) where the knowledge, effort, and abilities of diverse perspectives are leveraged (Eisenhardt, 1990).

\section{Acknowledgements}

An earlier version of this article was presented at the 2015 ISPIM Innovation Summit in Brisbane, Australia, December 6-9, 2015. ISPIM (ispim.org) - the International Society for Professional Innovation Management is a network of researchers, industrialists, consultants, and public bodies who share an interest in innovation management.

\section{About the Authors}

Tracy Stanley is currently completing her doctoral thesis at the Queensland University of Technology (QUT) in Brisbane, Australia, where she investigated how the characteristics of team work environments influence creative behaviours and employee engagement in a global project-based organization. The research was undertaken across five teams providing a range of finance, marketing, and engineering services. Tracy has twenty years of international experience in human resources and change management in Asia and Europe across industries including travel technology, government, financial services, education, and health. Her qualifications include an MBA from the University of Melbourne, Australia, and an MBus (Research) from QUT.
Judy Matthews is a Senior Lecturer at the Queensland University of Technology (QUT) Business School, in Brisbane, Australia, where she teaches both MBAs and senior executives on the topics of innovation management, facilitates problem framing and problem solving in complex environments, and uses design thinking to develop and execute new possibilities. Her enthusiasm for the importance of innovation management can be traced to her research into innovation systems in Australia, in public sector research and development, and in the management of change. For the last six years, Judy has been an active researcher and facilitator in the development and application of design mindsets and methods, recognizing that the frameworks, tools, and mindsets of designers can be used to help managers to problem solve and innovate in their businesses and develop new business models. Judy has published articles in a wide range of international journals, including the Journal of Business Research, International Journal of Technology Management, Innovation: Management, Policy and Practice, and Design Management Journal.

Paul Davidson is an Associate Professor at the Queensland University of Technology (QUT) Business School in Brisbane, Australia. He is a management specialist with over 25 years university teaching experience and 100 academic publications including two major textbooks in management. He has studied and taught at several universities, and in between academic appointments, he has been CEO of a company with 650 employees. At QUT since 1991, he has developed and delivered courses for high-profile corporate organizations in addition to extensive graduate teaching. Paul has received a number of awards for his teaching and academic publishing. He is a former President (2000-2005) of the Australian Human Resource Institute (Queensland). In academic administration, he served the Brisbane Graduate School of Business as Subject Area Coordinator for Management, HRM, and Organisational Behaviour, and managed the school's program for Defence Force students. From 2005 to 2012, he was Deputy Director of the QUT Project Management Academy, a joint initiative of the Science and Engineering faculty and the QUT Business School. He now leads the MBus(HRM) program. His research interests include the development of management competencies, knowledge management, and project management, as well as international human resource management. 


\section{Insights from Stimulating Creative Behaviours in a Project-Based Organization Team}

Tracy Stanley, Judy Matthews, and Paul Davidson

\section{References}

Amabile, T. M., Conti, R., Coon, H., Lazenby, J., \& Herron, M. 1996. Assessing the Work Environment for Creativity. The Academy of Management Journal, 39(5): 1154-1184.

http://dx.doi.org/10.2307/256995

Amabile, T. M., \& Gryskiewicz, N. D. 1989. The Creative Environment Scales: Work Environment Inventory. Creativity Research Journal, 2(4): 37-41.

http://dx.doi.org/10.1080/10400418909534321

Amabile, T. M., Hadley, C. N., \& Kramer, S. J. 2002. Creativity under the Gun. Harvard Business Review, 80: 52-63.

Anderson, N. R., \& West, M. A. 1998. Measuring Climate for Work Group Innovation: Development and Validation of the Team Climate Inventory. Journal of Organizational Behavior, 19(3): 235-258.

http://dx.doi.org/10.1002/(SICI) 1099-1379(199805)19:3<235::AIDJOB837>3.0.CO;2-C

Catmull, E. 2008. How Pixar Fosters Collective Creativity. Harvard Business Review, 86(9): 64-72.

Dul, J., \& Ceylan, C. 2011. Work Environments for Employee Creativity. Ergonomics, 54(1): 12-20.

http://dx.doi.org/10.1080/00140139.2010.542833

Dulaimi, M. F., Ling, F. Y., Ofori, G., \& Silva, N. D. 2002. Enhancing Integration and Innovation in Construction. Building Research \& Information, 30(4): 237-247.

http://dx.doi.org/10.1080/09613210110115207

Eisenhardt, K. M. 1989. Building Theories from Case Study Research. Academy of Management Review, 14(4): 532-550. http://dx.doi.org/10.2307/258557

Eisenhardt, K. M. 1990. Speed and Strategic Choice: How Managers Accelerate Decision Making. California Management Review, 32(3): 39-54.

http://dx.doi.org/10.2307/41166616

Gilson, L. L., \& Shalley, C. E. 2004. A Little Creativity Goes a Long Way: An Examination of Teams' Engagement in Creative Processes. Journal of Management, 30(4): 453-470. http://dx.doi.org/10.1016/j.jm.2003.07.001

Hackman, J. R. 2011. Collaborative Intelligence: Using Teams to Solve Hard Problems. San Francisco, CA: Berrett-Koehler Publishers.

Hartmann, A. 2006. The Role of Organizational Culture in Motivating Innovative Behaviour in Construction Firms. Construction Innovation, 6(3): 159-172.

http://dx.doi.org/10.1108/14714170610710712

Harvey, S., \& Kou, C.-Y. 2013. Collective Engagement in Creative Tasks: The Role of Evaluation in the Creative Process in Groups. Administrative Science Quarterly, 58(3): 346-386. http://dx.doi.org/10.1177/0001839213498591

Hennessey, B. A., \& Amabile, T. M. 2010. Creativity. Annual Review of Psychology, 61(1): 569-598.

http://dx.doi.org/10.1146/annurev.psych.093008.100416

IBM. 2010. Capitalizing Complexity: Insights from the Global Chief Executive Officer Study. Somers, NY: IBM Global Business Services.
Isaksen, S. G., \& Ekvall, G. 2010. Managing for Innovation: The Two Faces of Tension in Creative Climates. Creativity and Innovation Management, 19(2): 73-88. http://dx.doi.org/10.1111/j.1467-8691.2010.00558.x

Isaksen, S. G., Lauer, K. J., Ekvall, G., \& Britz, A. 2001. Perceptions of the Best and Worst Climates for Creativity: Preliminary Validation Evidence for the Situational Outlook Questionnaire. Creativity Research Journal, 13(2): 171-184. http://dx.doi.org/10.1207/S15326934CRJ1302_5

Jehn, K. A. 1995. A Multimethod Examination of the Benefits and Detriments of Intragroup Conflict. Administrative Science Quarterly, 40(2): 256-282. http://dx.doi.org/10.2307/2393638

Kanter, R. M. 1988. Three Tiers for Innovation Research. Communication Research, 15(5): 509-523.

http://dx.doi.org/10.1177/009365088015005001

Matthews, J. 2002. Innovation in Australian Small and Medium Enterprises: Contributions from Strategic Human Resource Management. Asia Pacific Journal of Human Resources, 40(2): 193-204.

http://dx.doi.org/10.1177/1038411102402004

Mumford, M. D., \& Gustafson, S. B. 1988. Creativity Syndrome: Integration, Application, and Innovation. Psychological Bulletin, 103(1): 27-43.

http://dx.doi.org/10.1037/0033-2909.103.1.27

Naggar, R. 2015. The Creativity Canvas: A Business Model for Knowledge and Idea Management. Technology Innovation Management Review, 5(7): 50-58.

http://timreview.ca/article/914

Pelled, L. H. 1996. Demographic Diversity, Conflict, and Work Group Outcomes: An Intervening Process Theory. Organization Science, 7(6): 615-631.

http://dx.doi.org/10.1287/orsc.7.6.615

Shalley, C. E., \& Gilson, L. L. 2004. What Leaders Need to Know: A Review of Social and Contextual Factors That Can Foster or Hinder Creativity. The Leadership Quarterly, 15(1): 33-53. http://dx.doi.org/10.1016/j.leaqua.2003.12.004

Smith, M., Busi, M., Ball, P., \& Van Der Meer, R. 2008. Factors Influencing an Organisation's Ability to Manage Innovation: A Structured Literature Review and Conceptual Model. International Journal of Innovation Management, 12(4): 655-676. http://dx.doi.org/10.1142/S1363919608002138

Stanley, T., Davidson, P., \& Matthews, J. 2014. Creative Work Environments and Employee Engagement: Exploring Potential Links and Possibilities. Zeszyty Naukowe Uniwersytetu Ekonomicznego w Krakowie, 9(933): 33-51. http://dx.doi.org/10.15678/ZNUEK.2014.0933.0903

Starbuck, W. H. 1992. Learning by Knowledge-Intensive Firms. Journal of Management Studies, 29(6): 713-740. http://dx.doi.org/10.1111/j.1467-6486.1992.tb00686.x

Taylor, A., \& Greve, H. R. 2006. Superman or the Fantastic Four? Knowledge Combination and Experience in Innovative Teams. Academy of Management Journal, 49(4): 723-740. http://dx.doi.org/10.5465/AMJ.2006.22083029 


\section{Insights from Stimulating Creative Behaviours in a Project-Based Organization Team}

Tracy Stanley, Judy Matthews, and Paul Davidson

Thompson, L. L., \& Choi, H.-S. 2005. Creativity and Innovation in Organizational Teams. Mahwah, NJ: Lawrence Erlbaum Associates, Inc., Publishers.

West, M. A. 2002. Sparkling Fountains or Stagnant Ponds: An Integrative Model of Creativity and Innovation Implementation in Work Groups. Applied Psychology, 51(3): 355-387.

http://dx.doi.org/10.1111/1464-0597.00951

Woodman, R. W., Sawyer, J. E., \& Griffin, R. W. 1993. Toward a Theory of Organizational Creativity. Academy of Management Review, 18(2): 293-321.

http://dx.doi.org/10.5465/AMR.1993.3997517

Citation: Stanley, T., Matthews, J., \& Davidson, P. 2016

Insights from Stimulating Creative Behaviours in a

Project-Based Organization Team. Technology

Innovation Management Review, 6(4): 26-33.

http://timreview.ca/article/979

Keywords: creative behaviours, work environments, teams, problem solving 